\title{
PENGARUH APLIKASI PUPUK HAYATI DAN PUPUK KANDANG (AYAM DAN SAPI) TERHADAP PERTUMBUHAN DAN HASIL TANAMAN SEMANGKA (Citrullus lanatus)
}

\section{THE EFFECT OF APLICATION OF BIOLOGICAL FERTILIZER AND MANURE (CHIKEN AND CATTLE) ON THE GROWTH AND PRODUCTION OF WATERMELONS (Citrullus lanatus)}

\author{
Masriyana*, Kus Hendarto, Sri Yusnaini, Yohannes C. Ginting \\ Jurusan Agroteknologi Fakultas Pertanian Universitas Lampung \\ Jalan Prof. Dr. soemantri Brojonegoro No.1 Bandar Lampung 35145 \\ *Email:masriyanaanna@yahoo.co.id
}

\begin{abstract}
Watermelon productivity in Lampung province is relatively low, because agricultural land in Lampung province is dominated by ultisol soil. To improve the fertility of ultisol soil for watermelon cultivation, it is necessary to add organic matter and biological fertilizer. The research aims to determine the effect of chicken manure, cattle manure and biofertilizer Grikulan plus application on the growth and yield of watermelons. This research was conducted at the Hajimena Agricultural Training Center, South Lampung in April 2019 - July 2019. The study used a Randomized Block Design (RBD) factorially arranged (3x3) with three groups and there were 9 treatment combinations. The result of this research showed that the application of bio-fertilizer on $20 \mathrm{ml} / \mathrm{l}$ concentration gave the best result on plant lenght, number of female flowers, fruit length, and fruit diameter compared with control plant (without bio-fertilizer). The application of 20 ton/ha manure (chicken and cattle) can increase the growth and yield component of watermelon. Its indicated by plant length, number of female flowers, fruit length, and fruit diameter. The highest was watermelon obtained by the combination of cow manure and bio-fertilizer on $20 \mathrm{ml} / \mathrm{l}$ concentration rather than without bio-fertilizer.
\end{abstract}

Keywords: Bio-fertilizer, cattle manure, chicken manure, watermelon

\begin{abstract}
ABSTRAK
Produktivitas semangka di provinsi Lampung tergolong rendah, karena lahan pertanian di provinsi Lampung didominasi tanah ultisol. Untuk meningkatkan kesuburan tanah ultisol dalam budidaya semangka diperlukan penambahan bahan organik dan pupuk hayati. Penelitian bertujuan untuk mengetahui pengaruh pemberian pupuk kandang ayam dan pupuk kandang sapi serta aplikasi pupuk hayati Grikulan plus pada pertumbuhan dan hasil tanaman semangka. Penelitian ini dilaksanakan di Balai Pelatihan Pertanian Hajimena, Lampung Selatan pada April 2019 - Juli 2019. Penelitian menggunakan Rancangan Acak Kelompok (RAK) yang disusun secara faktorial (3x3) dengan tiga kelompok dan terdapat 9 kombinasi perlakuan. Hasil penelitian menunjukkan bahwa perlakuan pupuk hayati memberikan hasil terbaik dengan konsentrasi $20 \mathrm{ml} / \mathrm{l}$ dibandingkan tanpa pemberian
\end{abstract}


pupuk hayati pada panjang tanaman, jumlah bunga betina, panjang buah, dan diameter buah. Pupuk kandang (ayam dan sapi) 20 ton/ha mampu meningkatkan pertumbuhan dan hasil tanaman semangka yang ditunjukkan oleh panjang tanaman, jumlah bunga betina, panjang buah, dan diameter buah. Produksi Semangka tertinggi diperoleh pada aplikasi pupuk kandang sapi jika disertai aplikasi pupuk hayati konsentrasi $20 \mathrm{ml} / 1$ dari pada tanpa pupuk hayati.

Kata kunci: Pupuk hayati, pupuk kandang ayam, pupuk kandang sapi, semangka

\section{PENDAHULUAN}

Tanaman semangka termasuk salah satu jenis tanaman buah-buahan semusim yang disukai semua lapisan masyarakat. Pengembangan budidaya komoditas ini mempunyai prospek cerah karena dapat mendukung upaya peningkatan pendapatan petani. Daya tarik budidaya semangka bagi petani terletak pada nilai ekonominya yang tinggi (Prahasta, 2009).

Kementrian Pertanian (2015) menyatakan bahwa produksi semangka di Indonesia tahun 2009 2014 mengalami peningkatan produksi. Produksi tahun 2009 sebesar 474.327 ton dengan luas panen 34.219 hektar dan produksi tahun 2014 sebesar 653.974 ton dengan luas panen 35.802 hektar. Dengan rata-rata produktivitas sebesar \pm 18 ton per hektar. Sedangkan potensi hasil tanaman semangka dapat mencapai lebih dari 30 ton per hektar, sehingga produktivitas tanaman semangka harus terus ditingkatkan.

Di provinsi Lampung, lahan pertanian didominasi olehjenis tanah ultisol, tanahultisol memiliki sifat keasaman tanah yang tinggi, (pH rata-rata 3-4,5), miskin kandungan unsur hara, kandungan bahan organik rendah dan kapasitas tukar kation rendah (Prasetyo dan Suriadikarta, 2006).

Pemberian bahan organik dan pupuk hayati pada lahan budidaya akan memperbaiki kesuburan tanah secara fisik, secara kimia, dan secara biologi (Dermiyati, 2015). Bahan organik berupa pupuk kandang ayam dan pupuk kandang sapi telah banyak digunakan dalam budidaya tanaman. Pupuk Hayati mengandung beberapa jenis mikroba yang mampu menyediakan hara bagi tanaman dan mengendalikan serangan penyakityang penyebarannya melalui tanah (Hasyim, 2015).

Tujuan penelitian adalah untuk mengetahui pengaruh pemberian pupuk kandang ayam dan pupuk kandang sapi dengan aplikasi konsentrasi pupuk hayati Grikulan plus serta interaksi antara kedua faktor perlakuan terhadap pertumbuhan dan produksi tanaman semangka (Citrullus lanatus).

\section{BAHAN DAN METODE}

Penelitian ini dilaksanakan di Balai Pelatihan Pertanian di Hajimena Natar, Lampung Selatan. Penelitian dilaksanakan pada April 2019 hingga Juli 2019. Bahan yang digunakan pada penelitian ini yaitu: benih semangka varietas inul hibrida (F1 Red Dragon), pupuk kandang ayam dengan kandungan hara yaitu $\mathrm{N}$ sebesar 3,22\%, P sebesar 9,34\%, dan K sebesar $0,218 \%$, pupuk kandang sapi dengan kandungan hara yaitu $\mathrm{N}$ sebesar 2,95\%, P sebesar 3,92\%, dan K sebesar $0,17 \%$ dan pupuk hayati dengan merk dagang Grikulan plus. Alat yang digunakan yaitu: tray 
persemaian, cangkul, selang, gembor, sprayer, kayu patok, label, paku payung, plastik, meteran, timbangan, gelas ukur, selang air, cangkul, kertas label, alat tulis, dan kamera digital.

Penelitian menggunakan Rancangan Acak Kelompok (RAK) yang disusun secara faktorial $(3 \times 2)$ dengan tiga kelompok dan terdapat 9 kombinasi perlakuan. Faktor pertama pupuk hayati $(\mathrm{H})$ terdiri dari tiga taraf yaitu: tanpa pupuk hayati (H0), pupuk hayati konsentrasi $10 \mathrm{ml} / \mathrm{l}(\mathrm{H} 1)$, dan pupuk hayati konsentrasi 20 ml/1(H2). Faktor kedua aplikasi pupuk kandang (B) terdiri dari tiga taraf yaitu: tanpa pupuk kandang (B0), aplikasi pupuk kandang ayam (B1), dan aplikasi pupuk kandang sapi (B2). Jumlah tanaman sampel sebanyak 64 tanaman, tiap perlakuan yang sama di tiap ulangan diambil dua sampel tanaman untuk diamati. Homogenitas ragam diuji dengan uji Bartlett dan additivitas data diuji dengan uji Tukey, kemudian data dianalisis dengan sidik ragam dan dilanjutkan dengan uji BNJ pada taraf 5\%. Variabel yang diamati yaitu panjang tanaman, jumlah cabang, jumlah bunga betina, bobot buah rata-rata, produksi buah per petak, panjang buah, diameter buah, kandungan hara tanah.

\section{HASIL DAN PEMBAHASAN}

Hasil penelitian menunjukan bahwa aplikasi pupuk hayati dan pupuk kandang (ayam dan sapi) serta interaksinya berpengaruh nyata terhadap pertumbuhan dan hasil tanaman semangka.

Aplikasi pupuk hayati berbeda nyata dengan tanpa pupuk hayati pada variabel; panjang tanaman, jumlah bunga betina, diameter buah dan panjang buah. Aplikasi pupuk hayati konsentrasi $20 \mathrm{ml} / 1$ dan konsentrasi $10 \mathrm{ml} / \mathrm{l}$ tidak berpengaruh nyata, kecuali pada bunga betina (Tabel 1)

Pemberian pupuk kandang (ayam dan sapi) menghasilkan panjang tanaman, jumlah bunga betina, panjang buah dan diameter buah yang berbeda dengan tanpa pupuk kandang. Pupuk kandang sapi menghasilkan diameter buah yang lebih besar dibandingkan pupuk kandang ayam, sedangkan pada variabel lain tidak berbeda (Tabel 2).

Interaksi aplikasi pupuk hayati dan pupuk kandang terjadi pada bobot per buah dan bobot buah per petak tanaman semangka. Pupuk kandang sapi dengan aplikasi pupuk hayati $20 \mathrm{ml} / 1$ menghasilkan bobot perbuah sebesar 2.454,66 gram dan bobot buah perpetak

Tabel 1. Pengaruh pupuk hayati terhadap panjang tanaman $7 \mathrm{mst}$,jumlah bunga betina, panjang buah, dan diameter buah

\begin{tabular}{lcccc}
\hline Pupuk Hayati & $\begin{array}{c}\text { Panjang tanaman } \\
7 \mathrm{mst}(\mathrm{cm})\end{array}$ & $\begin{array}{c}\text { Jumlah bunga } \\
\text { betina }\end{array}$ & $\begin{array}{c}\text { Panjang buah } \\
(\mathrm{cm})\end{array}$ & $\begin{array}{c}\text { Diameter buah } \\
(\mathrm{cm})\end{array}$ \\
\hline Tanpa pupuk hayati & $237,2 \mathrm{~b}$ & $3,38 \mathrm{c}$ & $17,01 \mathrm{~b}$ & $10,26 \mathrm{~b}$ \\
Pupuk hayati 10 ml/1 & $290,5 \mathrm{a}$ & $3,78 \mathrm{~b}$ & $20,09 \mathrm{a}$ & $11,72 \mathrm{a}$ \\
Pupuk hayati 20 ml/1 & $293,5 \mathrm{a}$ & $4,11 \mathrm{a}$ & $21,02 \mathrm{a}$ & $11,71 \mathrm{a}$ \\
\hline BNJ 5\% & 11,58 & 0,26 & 1,70 & 0,60 \\
\hline
\end{tabular}

Keterangan: Nilai tengah yang diikuti oleh huruf yang sama tidak berbeda berdasarkan uji beda nyata jujur (BNJ) pada kolom yang sama pada taraf $5 \%$. 
Tabel 2. Pengaruh dosis pupuk kandang (ayam dan sapi) terhadap panjang tanaman $7 \mathrm{mst}$, jumlah bunga betina, panjang buah, dan diameter buah

\begin{tabular}{lcccc}
\hline \multicolumn{1}{c}{ Pupuk kandang } & $\begin{array}{c}\text { Panjang tanaman } \\
7 \mathrm{mst}(\mathrm{cm})\end{array}$ & $\begin{array}{c}\text { Jumlah bunga } \\
\text { betina }\end{array}$ & $\begin{array}{c}\text { Panjang buah } \\
(\mathrm{cm})\end{array}$ & $\begin{array}{c}\text { Diameter buah } \\
(\mathrm{cm})\end{array}$ \\
\hline Tanpa Pupuk Kandang & $250,5 \mathrm{~b}$ & $3,22 \mathrm{~b}$ & $17,21 \mathrm{~b}$ & $10,40 \mathrm{c}$ \\
Pupuk Kandang Ayam & $290,7 \mathrm{a}$ & $3,94 \mathrm{a}$ & $20,54 \mathrm{a}$ & $11,05 \mathrm{~b}$ \\
Pupuk Kandang Sapi & $280,0 \mathrm{a}$ & $4,11 \mathrm{a}$ & $21,47 \mathrm{a}$ & $12,26 \mathrm{a}$ \\
\hline BNJ 5\% & 11,58 & 0,26 & 1,70 & 0,60 \\
\hline
\end{tabular}

Keterangan: Nilai tengah yang diikuti oleh huruf yang sama tidak berbeda berdasarkan uji beda nyata jujur (BNJ) pada kolom yang sama pada taraf $5 \%$.

Tabel 3. Pengaruh interaksi aplikasi pupuk pupuk hayati dengan pupuk kandang (ayam dan sapi) terhadap bobot buah semangka rata-rata

\begin{tabular}{lccc}
\hline \multicolumn{1}{c}{ Perlakuan } & $\begin{array}{c}\text { Tanpa Pupuk Kandang } \\
\left(\mathrm{B}_{0}\right)\end{array}$ & $\begin{array}{c}\text { Pupuk Kandang } \\
\text { Ayam }\left(\mathrm{B}_{1}\right)\end{array}$ & $\begin{array}{c}\text { Pupuk Kandang } \\
\text { Sapi }\left(\mathrm{B}_{2}\right)\end{array}$ \\
\hline & $672,16 \mathrm{~b}$ & (gram) \\
\hline Tanpa Pupuk Hayati $\left(\mathrm{H}_{0}\right)$ & $\mathrm{B}$ & $1117,88 \mathrm{~b}$ & $1086,33 \mathrm{c}$ \\
& $1090,83 \mathrm{a}$ & $\mathrm{A}$ & $\mathrm{A}$ \\
Pupuk Hayati Konsentrasi 10m/ $/ \mathrm{L}\left(\mathrm{H}_{1}\right)$ & $\mathrm{B}$ & $1589,00 \mathrm{a}$ & $1669,00 \mathrm{~b}$ \\
& $979,33 \mathrm{ab}$ & $\mathrm{A}$ & $\mathrm{A}$ \\
Pupuk Hayati Konsentrasi 20m/ $/ \mathrm{L}\left(\mathrm{H}_{2}\right)$ & $\mathrm{C}$ & $\mathrm{B}$ & $2454,66 \mathrm{a}$ \\
\hline BNJ 5\% & & 333,33 & $\mathrm{~A}$ \\
\hline
\end{tabular}

Keterangan: Angka sebaris yang diikuti oleh huruf besar yang sama tidak berbeda nyata pada taraf uji BNJ 5\%. Angka sekolom yang diikuti oleh huru kecil yang sama tidak berbeda nyata pada taraf uji BNJ 5\%.

sebesar 14.728 gram, tetapi berbeda dengan pupuk kandang ayam serta tanpa pupuk kandang (Tabel3 dan 4)

\section{Pembahasan}

Aplikasi pupuk hayati berpengaruh terhadap pertumbuhan dan hasil tanaman semangka, dikarenakan pupukhayatiGrikulanplus yang diaplikasikanmengandung berbagai jenis mikroba diantaranya Azospirillumsp.,Azotobacter sp., lactobacillus sp., Pseudomonas sp., dan mikroba pelarut phosfat (Gunarto, 2015).

Menurut Simanungkalit (2001), mikroba Azospirillum sp. dan Azotobacter sp. dapat memfiksasi nitrogen dari udara. Ketersediann nitrogen menjadikan pertumbuhan panjang tanaman yang lebih panjang. Mikroorganisme pelarut phosfat, Lactobacillus sp. dan pseudomonas sp. akan menghasilkan asam organik diantaranya; asam sitrat, glutamate, suksinat, laktat, glioksalat, malat, tumarat, dan ktobutirat (Rao, 1982). Menurut Premono (1994) asam-asam organik tersebut akan membentuk senyawa komplek dengan ion Fe dan Al sehingga unsur phosfat akan disebabkan dan menjadi tersedia tersedia bagi tanaman.

Pupuk kandang adalah bahan organik yang berperan dalam memperbaiki sifat fisik, kimia dan biologi tanah (Suliasih dan muharam, 2010; Dermiyati, 2015). 
Tabel 4. Pengaruh interaksi aplikasi pupuk pupuk hayati dengan pupuk kandang (ayam dan sapi) terhadap produksi buah semangka per petak

\begin{tabular}{lccc}
\hline \multicolumn{1}{c}{ Perlakuan } & $\begin{array}{c}\text { Tanpa Pupuk Kandang } \\
\left(\mathrm{B}_{0}\right)\end{array}$ & $\begin{array}{c}\text { Pupuk Kandang Ayam } \\
\left(\mathrm{B}_{1}\right)\end{array}$ & $\begin{array}{c}\text { Pupuk Kandang Sapi } \\
\left(\mathrm{B}_{2}\right)\end{array}$ \\
\hline & $4033 \mathrm{~b}$ & $($ gram $)$ & \\
\hline Tanpa Pupuk Hayati $\left(\mathrm{H}_{0}\right)$ & $\mathrm{B}$ & $6707 \mathrm{~b}$ & $6518 \mathrm{c}$ \\
& $6563 \mathrm{a}$ & $\mathrm{A}$ & $\mathrm{A}$ \\
Pupuk Hayati Konsentrasi 10m//L $\left(\mathrm{H}_{1}\right)$ & $\mathrm{B}$ & $9071 \mathrm{a}$ & $10014 \mathrm{~b}$ \\
& $5876 \mathrm{a}$ & $\mathrm{A}$ & $\mathrm{A}$ \\
Pupuk Hayati Konsentrasi 20m/ $/ \mathrm{L}\left(\mathrm{H}_{2}\right)$ & $\mathrm{C}$ & $8997 \mathrm{a}$ & $14728 \mathrm{a}$ \\
\hline BNJ 5\% & & $\mathrm{B}$ & $\mathrm{A}$ \\
\hline
\end{tabular}

Keterangan: Angka sebaris yang diikuti oleh huruf besar yang sama tidak berbeda nyata pada taraf uji BNJ 5\%. Angka sekolom yang diikuti oleh huru kecil yang sama tidak berbeda nyata pada taraf uji BNJ 5\%.

Pupuk kandang yang diaplikasikan berdasarkan hasil analisis laboratorium mengandung unsur hara NPK dan C-Organik. Pupuk kandang ayam yang mengandung C-Organik $=13.11 \%, \mathrm{~N}=3,22 \%, \mathrm{P}=9,34 \%, \mathrm{~K}=$ $0,21 \%$ dan pupuk kandang sapi mengandung $\mathrm{C}$ Organik $=7,55 \%, \mathrm{~N}=2,95 \%, \mathrm{P}=3,92 \%, \mathrm{~K}=0,17 \%$ (Hasil analisa bahan, laboratorium tanah Polinela, 2019). Adanya kandungan unsur hara NPK pada pupuk kandang tersebut akan menambah kandungan unsur hara dalam tanah bagi pertumbuhan dan hasil semangka. Menurut Jamin (2002), tingginya unsur hara N,P, dan K dari pupuk kandang akan menghasilkan pembentukan sel secara cepat dan produk fotosintat akan menghasilkan besar yang ditranslokasikan keseluruh bagian tanaman termasuk pertumbuhan buah.

Berdasarkan hasil analisis ragam, terjadi interaksi antara aplikasi pupuk hayati dan pupuk kandang terhadap bobot buah dan produksi buah semangka perpetak. Pemberian pupuk kandang sapi disertai pupuk hayati konsentras $20 \mathrm{ml} / 1$ memberikan hasil yang lebih tinggi dari pemberian pupuk kandang ayam. Perbedaan produksi yang dihasilkan oleh perlakuan pupuk kandang sapi dan pupuk kandang ayam diduga karena adanya perbedaan sifat fisik tanah seperti kadar air tanah, suhu tanah dan C-Organik tanah yang terjadi akibat aplikasi pupuk hayati. Perlakuan pupuk kandang sapi memberikan kandunngan air tanah sebesar 28,94\% lebih tinggi dibandingkan pupuk kandang ayam sebesar $25,18 \%$, suhu tanah pupuk kandang sapi sebesar $27,57^{\circ} \mathrm{C}$ lebih rendah dibandingkan pupuk kandang ayam sebesar $28,12^{\circ} \mathrm{C}$, dan C-Organik pupuk kandang sapi lebih tinggi sebesar $1,81 \%$ dibandingkan pupuk kandang ayam sebesar $1,18 \%$.

Produktivitas semangka yang dihasilkan dari penelitian ini,jika dikonversikan. Pada perlakuan pupuk kandang sapi dengan pupuk hayati sebesar $14.728 \mathrm{~kg} /$ ha. Sedangkan pupuk kandang ayam dengan pupuk hayati sebesar $8.997 \mathrm{~kg} /$ ha dan tanpa pupuk kandang sebesar $5.896 \mathrm{~kg} / \mathrm{ha}$. 


\section{KESIMPULAN}

Simpulan dari hasil penelitian ini yaitu pemberian pupuk hayati Grikulan plus memberikan hasil terbaik dengan konsentrasi $20 \mathrm{ml} / \mathrm{l}$ dibandingkan tanpa pemberian pupuk hayati pada panjang tanaman, jumlah bunga betina, panjang buah, dan diameter buah. Pupuk kandang (ayam dan sapi) 20 ton/ha mampu meningkatkan pertumbuhan dan hasil tanaman semangka yang ditunjukkan oleh panjang tanaman, jumlah bunga betina, panjang buah, dan diameter buah. Produksi Semangka tertinggi diperoleh pada aplikasi pupuk kandang sapi jika disertai aplikasi pupuk hayati

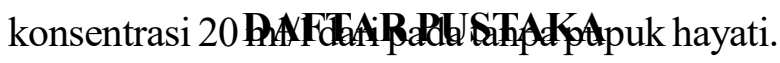

Dermiyati. 2015. Sistem Pertanian Organik Berkelanjutan. Plantaxia. Yogyakarta. $121 \mathrm{hlm}$.

Gunarto, L. 2015. Bio Max Grow Tanaman. Kementrian Pertanian Republik Indonesia. Jakarta.

Hasyim, A, W Setiawati, dan LLukman. 2015. Inovasi teknologi pengendalian OPT ramah lingkungan: Upaya alternatif menuju ekosistem harmonis. Pengembangan Inovasi Pertanian. 8 (1): 110.
Jumin, H. B. 2002. Agroekologi: Suatu Pendektan Fisiologis. Rajawali Press. Jakarta. 179 hlm.

Kementrian Pertanian. 2015. Outlook Komoditas Pertanian Subsektor Hortikultura Semangka. Sekjen Pusat Data dan Informasi Pertanian. Jakarta. $53 \mathrm{hlm}$.

Prahasta, A.S. 2009. Agribisnis Semangka. Pustaka Grafika: Bandung.

Prasetyo, BH dan Suryadikarta. 2006. Karakteristik Potensi dan Teknologi Penolahan Tanah Ultisol untuk Pengembangan Petanian Lahan Kering di Indonesia. Jurnal Litbang Pertanian. 25(2):34-37.

Premono, M.E. 1994. Jasad Renik Pelarut P: Pengaruhnya terhadap P-tanah dan Efisiensi Pemupukan P Tanaman Tebu [disertasi]. Institut Pertanian Bogor, Program Pascasarjana. Bogor.

Rao. 1994. Mikroorganisme Tanah dan Pertumbuhan. UI. Press. Jakarta.

Simanungkalit, R.D.M. 2001. Aplikasi Pupuk Hayati dan Pupuk Kimia; Suatu Pendekatan Terpadu. Jurnal Agrobiol. 4:56-61.

Suliasih, S.W., danA. Muharam. 2010.Aplikasi pupuk organik dan bakteri pelarut fosfat untuk meningkatkan pertumbuhan tanaman tomat dan aktivitas mikroba tanah. Jurnal Hortikultura. 20 (2): 241-6. 